American Journal of Biochemistry and Biotechnology 4 (3): 239-244, 2008

ISSN 1553-3468

(C) 2008 Science Publications

\title{
The Antidiabetic Efficacy of Combined Extracts from Two Continental Plants: Azadirachta indica (A. Juss) (Neem) and Vernonia amygdalina (Del.) (African Bitter Leaf)
}

\author{
Patrick Ekong Ebong, Item Justin Atangwho, Eyong Ubana Eyong and Godwin Eneji Egbung \\ Department of Biochemistry, College of Medical Sciences, \\ University of Calabar P.M.B 1115, Calabar, Nigeria
}

\begin{abstract}
Polyherbal therapy is said to be a current pharmacological principle having the advantage of producing maximum therapeutic efficacy with minimum side effects. We assessed the antidiabetic efficacy and hence the impact on biochemical indices of toxicity by a combination of extracts from neem and bitterleaf. Thirty rats, 25 diabetic and 5 non-diabetic rats, were used for the study. The diabetic rats were divided equally into five groups and respectively treated: saline (diabetic control), extracts from neem and bitterleaf combined, neem only, bitterleaf only and chlorpropamide for a 24 day period. After oral administration of the first dose of extract $\left(400 \mathrm{mg} \mathrm{kg}^{-1}\right.$ b.w.) and chlorpropamide (4.286 mg kg-1 b.w.), blood glucose was monitored in vivo at various time intervals for $9 \mathrm{~h}$, thereafter daily administration continued for 24 days. Whereas single dose treatment with neem only showed peak reduction $(28.56 \%)$ an hour after, treatments with combined extracts, bitterleaf and chlorpropamide had their peak reductions all at the 7 th hour $(24.78,47.31$ and $60.51 \%$, respectively). Percentage reductions in blood glucose relative to their initial values at the end of treatment were $71.05,44.95,88.63$ and 75.83 for combined extract, neem, bitterleaf and chlorpropamide respectively. The decrease in blood glucose for the groups treated with combined extracts and bitterleaf only compared well $(\mathrm{p}<0.01)$ with chlorpropamide and non diabetic control, but not with neem alone. Determination of markers of hepatotoxicity in serum including GPT and GOT activities, total protein, albumin and urea indicated that, of the four treatments, neem provides the best protection against hepatic dysfunction. In the group treated with combined extracts these alternate selective advantages of neem and bitterleaf were expressed as a positive synergy, hence more beneficial than individual treatments.
\end{abstract}

Key words: Polyherbal therapy, Azadirachta indica, Vernonia amygdalina, diabetes mellitus, blood lucose

\section{INTRODUCTION}

Medicinal plants have formed the basis of health care throughout the world since the earliest days of humanity and are still widely used and have considerable importance in international trade ${ }^{[1]}$. In certain African countries for instance, up to $90 \%$ of the population still relies exclusively on plants as a source of medicines ${ }^{[2]}$. As a consequence, the World Health Organization (WHO) had in one of its charters in Geneva recommended further investigation into this area, particularly as it concerns chronic and debilitating diseases such as diabetes mellitus ${ }^{[3]}$.

A complex disease like diabetes mellitus, where little is talked about in aspects of prevention and curation, but rather management, there is an increased focus on plants in the search for appropriate hypoglycemic/antihyperglycemic agents. Firstly, because of leads provided by traditional medicine to natural products that may be better treatments than currently used conventional drugs ${ }^{[4]}$. Secondly the plants by secondary metabolic means contain a variety of herbal and non-herbal ingredients that are thought to act on a variety of targets by various modes and mechanisms ${ }^{[5]}$-given the multi-factorial pathogenicity of the disorders. Moreover, polyherbal therapies the combination of various types of agents from different plant sources, can be used to enhance efficacy. According to Tiwari and $\mathrm{Rao}^{[5]}$ polyherbal therapies have the synergistic, potentiative, agonistic/antagonistic pharmacological agents within themselves, that work together in a dynamic way to produce therapeutic efficacy with minimum side effects.

Corresponding Author: Patrick E. Ebong, Department of Biochemistry, College of Medical Sciences, University of Calabar P.M.B 1115, Calabar, Nigeria 
It is in this light that this work was designed to investigate the antidiabetic efficacy of combined extracts from two most widely used plants Azadirachta indica and Vernonia amygdalina, employed traditionally in the management of diabetes in Asia and the African sub-Region, respectively.

A. indica, normally found in the Indian subcontinent and the dry forest areas of South and Southeast Asia including Pakistan, Sri Lanka, Thailand, Malaysia and Indonesia, but cultivated in most other countries of the world belongs to the plant family Meliaceae ${ }^{[6]}$. Biswas et al. ${ }^{[7]}$ have reviewed the biological activities and medicinal properties of the plant and articulated, the hypoglycemic effects of its leaves, stem and bark and seed oil.

On the otherhand, V. amygdalina is a compositae both of wild and domestic browse in Africa. The plant has a reputation in its use in traditional management of diabetes in Southern Nigeria ${ }^{[8]}$. An earlier study in our laboratory compared the effect of extracts from the two plants separately on beta cell integrity in rats pretreated with alloxan, a beta cell destructive agent ${ }^{[9]}$. The present study compared the antidiabetic efficacies of combined extracts from the two plants with the plant extracts taken singly and also with a conventional sulfonylurea, chlorpropamide. Since hyperglycemia increases the generation of free radicals by glucose auto-oxidation and this increment of free radicals usually would lead to organ damage ${ }^{[10]}$, we also assessed indices of liver function/toxicity at the end of these treatments.

\section{MATERIALS AND METHODS}

Preparation of plants extracts: Matured leaves of $V$. amygdalina and $A$. indica were obtained from the Endocrine Research Farm of the University of Calabar, Calabar and University of Calabar staff quarters, respectively. Four hundred grammes $(400 \mathrm{~g})$ of each was separately mixed with $80 \%$ ethanol and homogenized using an electric homogenise. The homogenates were allowed in a refrigerator $\left(4^{\circ} \mathrm{C}\right)$ for $48 \mathrm{~h}$ and thereafter filtered using a chess material. The filtrates were concentrated at low temperature $\left(37^{\circ} \mathrm{C}\right)$ under reduced pressure using a rotary evaporator to one tenth of their original volumes. These were then allowed in a water bath at $37^{\circ} \mathrm{C}$ for complete evaporation to dryness ${ }^{[11]}$ yielding $36.48 \mathrm{~g}(9.12 \%)$ and $24.84 \mathrm{~g}(6.21 \%)$, respectively for $V$. amygdalina and A. indica.

Experimental animals and alloxan-induction of diabetes: Thirty healthy albino Wistar rats (males and females) obtained from the animal house, Department of Zoology, University of Calabar, Calabar after due permission from the Faculty Animal Ethics Committee were used for the study. The rats were allowed one week to acclimatize to Biochemistry departmental animal house, where they were housed throughout the experiment in polycarbonated cages. The animal housing facility was maintained at standard conditions: temperature $\left(28 \pm 2^{\circ} \mathrm{C}\right)$, relative humidity $(50 \pm 5 \%)$ and a $12 \mathrm{~h} \mathrm{light/dark} \mathrm{cycle.} \mathrm{Water} \mathrm{and} \mathrm{commercial} \mathrm{palletized}$ diet were available to the animals ad libitum throughout the treatment period. Twenty-five of the animals were induced with diabetes by injecting $150 \mathrm{mg} \mathrm{kg}^{-1}$ body weight of alloxan monohydrate (Sigma St. Louis, MO, USA) intraperitoneally. Ninety-six (96hrs) after, rats confirmed diabetic (i.e., random blood glucose $\geq 200 \mathrm{mg} \mathrm{dL}^{-1}$ ) were selected for the experiment.

Extract and drug administration: Before use, the extracts were reconstituted in normal saline (vehicle) and administered orally via gastric intubation at a dose of $400 \mathrm{mg} \mathrm{kg}^{-1} \mathrm{~b}$. w. for single extract treatment and $200 \mathrm{mg} \mathrm{kg}^{-1}$ each in combined extracts treatment. Chlorpropamide was administered at a dose of $14.286 \mathrm{mg} \mathrm{kg}^{-1}$ b. w. to simulate human regimens. The dosage of the extracts was determined from preliminary studies in our laboratory. The controls received normal saline (placebo).

Experimental design: The design consisted of 30 rats (25 surviving diabetic rats and 5 normal rats) divided into 6 groups of 5 rats each. Groups 1 and 2, normal and diabetic control rats given placebo treatment, Group 3: diabetic rats treated with combined extracts from A. indica and V. amygdalina, Group 4: diabetic rats treated with extract from A. indica only, Group 5: diabetic rats treated with extract from $V$. amygdalina only and Group 6: diabetic rats administered chlorpropamide. After first oral dose administration of extracts/drug, in vivo measurement of blood glucose was done with blood obtained from tail vein of the rat at $1,3,5,7$ and $9 \mathrm{~h}$ using One Touch ${ }^{\circledR}$ Glucometer (Lifescan, Inc., 1995 Milpitas, California 95035, USA). The oral administration then was continued twice per day in a $12 \mathrm{~h}$ cycle (6: am and 6: pm) for 24 days. At the end of the 24 day period, the animals were fasted for $12 \mathrm{~h}$, then anaesthetized under chloroform vapour and dissected. Whole blood obtained by cardiac puncture into plane tubes was allowed to clot for about $2 \mathrm{~h}$ and thereafter centrifuged (3,000 g for $10 \mathrm{~min})$ to remove cells and recover serum, which was used for the biochemical assays. 
Biochemical analysis: GPT (Glutamic Pyruvic Transaminase) and GOT (Glutamic Oxaloacetic Transaminase) assay kits were obtained from Randox Laboratories Ltd., Admore Diamond Road, Crumin Co. Antrim, UK. The assay methods are based on transamination reaction in which the concentrations of pyruvate (GPT) and oxaloacetate (GOT) hydrazones formed in the presence of 2,4 dinitrophenyl-hydrazone are measured at $546 \mathrm{~nm}^{[12]}$. Assay kits for total protein, albumin and urea determination were obtained from DIALAB Produktion und Vertrieb von chemischtechnischen, produktion und laborinstriementen Gesellschaft m.b.H. A-1160 Wien-panikengasse, Austria. Total protein in samples were measured by the method based on biuret reaction ${ }^{[13]}$ whereas that of albumin relies on the binding of bromcresol green (BCG) to albumin ${ }^{[14]}$. Urea determination in the method was based on urea hydrolysis by urease enzyme ${ }^{[14]}$.

Statistical analysis: The results were analysed for statistical significance by one-way ANOVA using the SPSS statistical program and Post Hoc Test (LSD) between groups using MS excel program. All data were expressed as Mean \pm SEM. $P$ values $<0.01$ and 0.05 were considered significant.

\section{RESULTS}

Effect of extracts/drug on blood glucose level: Table 1 shows effect of a single dose treatment on blood glucose determined at various time intervals for $9 \mathrm{~h}$. The values in parenthesis are percent change in blood glucose (\%BG):

$$
\% \mathrm{BG}=\mathrm{G}_{\mathrm{t}} \times 100 / \mathrm{G}_{\mathrm{o}}
$$

Where $G_{o}$ and $G_{t}$ are glucose levels at time o and $t$, respectively. Four days after alloxan-treatment, blood glucose of diabetic rats was significantly raised by 5.4-9 times the value of the normal control rats. First dose treatment caused reduction over the intervals monitored but with significant peak reductions at 1hour for A. indica treated group (28.56\%) and at 7th hour for combined extracts treatment $(24.78 \%), V$. amygdalina alone $(47.31 \%)$ and chlorpropamide $(60.51 \%)$ treated groups (Fig. 1). At the end of the chronic treatment period (24 days) decreases in blood glucose level relative to their initial values ( $96 \mathrm{~h}$ past alloxan values) of $71.05,44.95,88.63$ and $75.83 \%$ were observed in groups treated with $A$. indica and $V$. amygdalina combined, A. indica, $V$. amygdalina and chlorpropamide, respectively (Fig. 2). These reductions were significant at $\mathrm{p}<0.01$ except in the group treated

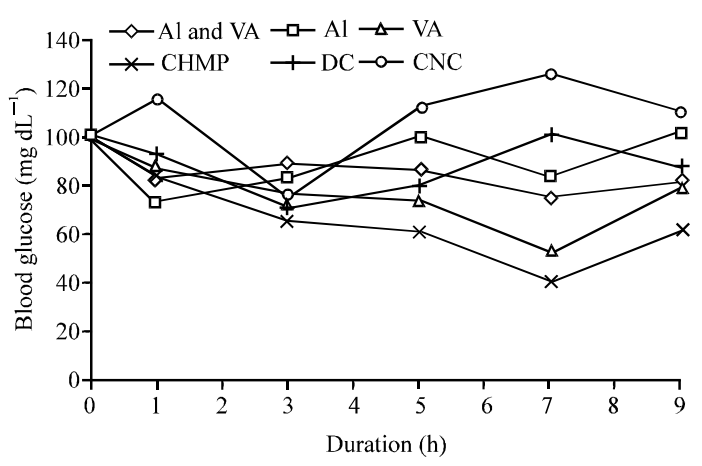

Fig. 1: Percentage of effect of plant extracts/drug on blood glucose levels monitored at various time intervals for $9 \mathrm{~h}$, compared with $0 \mathrm{~h}$ data in diabetic rats $(\%)$. Values are mean percent of blood glucose concentrations $(\mathrm{n}=5)$. AIA.indica, $\mathrm{VA}=\mathrm{V}$. amygdalina, $\mathrm{CHMP}=$ Chlorpropamide, $\mathrm{DC}=$ Diabetic control and $\mathrm{NC}$ $=$ normal control

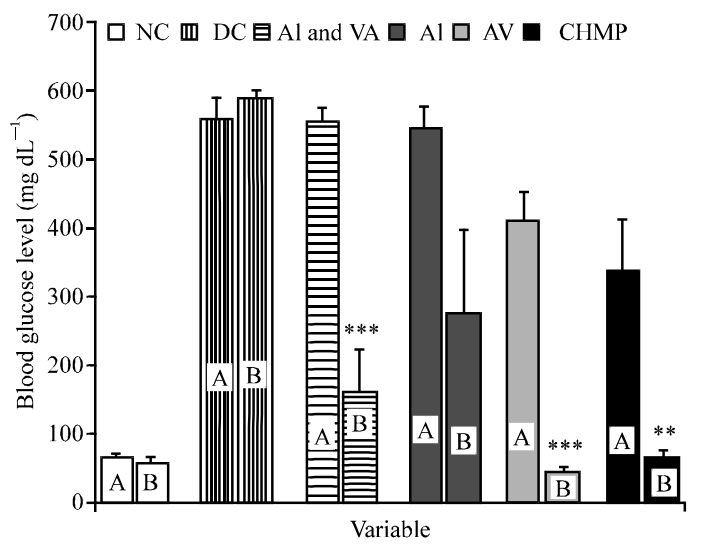

Fig. 2: Blood glucose level after 24 day $t / m$ with combined extracts, $A$. indica only and $V$. amygdalina only and chloropropamide in diabetic rat models. A, B: Blood glucose level before and after 24 day treatment. ** $\mathrm{p}<0.01$; $* * * \mathrm{p}<0.001$ vs A

with A. indica. The 24 day blood glucose levels show significant reduction $(\mathrm{p}<0.01)$ in all the treated groups compared to the diabetic control. Compared to normal control, A. indica treated group yet had blood glucose significantly higher $(\mathrm{p}<0.05)$, unlike the other 3 treatments that compared well with it at $(\mathrm{p}<0.05)$ (Fig. 3).

Effect of drug/extract treatment on some serum biochemical indices: Table 2 shows results of 
Am. J. Biochem. \& Biotech., 4 (3): 239-244, 2008

Table 1: Effect of drug/plant extracts on the blood glucose level $\left(\mathrm{mg} \mathrm{kg}^{-1}\right)$ of alloxan induced diabetic rats

\begin{tabular}{llllccc}
\hline GRP & $0 \mathrm{~h}$ & $1 \mathrm{~h}$ & $3 \mathrm{~h}$ & $5 \mathrm{~h}$ & $7 \mathrm{~h}$ & $9 \mathrm{~h}$ \\
\hline GRP 1 & $62.0 \pm 5.29$ & $69.8 \pm 4.13$ & $56.8 \pm 4.01$ & $66.8 \pm 4.58$ & $75.4 \pm 5.55$ & $66.2 \pm 4.77$ \\
& $(100)$ & $(114.84 \pm 8.17)$ & $(74.59 \pm 15.47)$ & $(112.16 \pm 14.09)$ & $(125.09 \pm 13.40)$ & $(109.37 \pm 10.13)$ \\
GRP 2 & $558.5 \pm 29.95$ & $512.8 \pm 34.34$ & $396.5 \pm 61.96$ & $445.0 \pm 56.36$ & $556.0 \pm 41.38$ & $484.3 \pm 95.91$ \\
& $(100)$ & $(92.07 \pm 4.11)$ & $(71.41 \pm 9.56)$ & $(79.96 \pm 8.23$ & $(100.54 \pm 8.78)$ & $(87.30 \pm 15.63)$ \\
GRP 3 & $558.6 \pm 19.70$ & $459.6 \pm 29.70$ & $495.6 \pm 46.91$ & $482.6 \pm 60.53$ & $418.2 \pm 74.51$ & $451.2 \pm 66.47$ \\
& $(100)$ & $(82.33 \pm 5.40)$ & $(88.98 \pm 8.48$ & $(86.42 \pm 10.84)$ & $(75.22 \pm 13.81)$ & $(80.96 \pm 12.39)$ \\
GRP 4 & $545.4 \pm 34.11$ & $375.8 \pm 63.83$ & $450.0 \pm 40.87$ & $531.2 \pm 31.30$ & $435.4 \pm 29.99$ & $544.2 \pm 20.73$ \\
& $(100)$ & $(71.44 \pm 14.54)$ & $(83.05 \pm 6.56)$ & $(100.00 \pm 11.71)$ & $(82.59 \pm 11.82)$ & $(80.96 \pm 12.39)$ \\
GRP 5 & $412.2 \pm 40.60$ & $353.4 \pm 76.64$ & $315.0 \pm 56.96$ & $308.6 \pm 54.76$ & $213.0 \pm 31.12$ & $314.4 \pm 58.67$ \\
& $(100)$ & $(87.13 \pm 19.20)$ & $(77.00 \pm 12.98)$ & $(73.78 \pm 8.08)$ & $(52.69 \pm 8.38)$ & $(79.60 \pm 19.15)$ \\
GRP 6 & $335.2 \pm 74.94$ & $302.2 \pm 92.00$ & $242.6 \pm 82.72$ & $233.2 \pm 96.20$ & $142.8 \pm 52.38$ & $236.0 \pm 98.22$ \\
& $(100)$ & $(82.68 \pm 12.83)$ & $(64.73 \pm 12.19)$ & $(61.26 \pm 11.71)$ & $(39.49 \pm 6.67)$ & $(61.87 \pm 14.58)$ \\
\hline
\end{tabular}

Mean \pm SEM, $n=5$

Table 2: Effect of drug/plant extracts on some serum biochemical indices

\begin{tabular}{|c|c|c|c|c|c|}
\hline$\overline{\text { GROUP }}$ & GPT (Unit L L $^{-1}$ ) & GOT (Unit L ${ }^{-1}$ ) & Total protein $\left(\mathrm{g} \mathrm{dL}^{-1}\right)$ & Albumin $\left(\mathrm{g} \mathrm{dL}^{-1}\right)$ & Urea $\left(\mathrm{mg} \mathrm{dL}^{-1}\right)$ \\
\hline$\overline{\text { GRP } 1}$ & $4.22 \pm 0.67$ & $5.85 \pm 1.33$ & $7.68 \pm 0.15$ & $2.88 \pm 0.19$ & $36.85 \pm 4.11$ \\
\hline GRP 2 & $15.50 \pm 0.73$ & $74.00 \pm 5.14$ & $7.17 \pm 0.24$ & $2.84 \pm 0.18$ & $118.98 \pm 10.38$ \\
\hline GRP 3 & $6.40 \pm 0.70 *$ & $13.88 \pm 2.88^{*}$ & $7.15 \pm 0.36$ & $3.17 \pm 0.11$ & $73.88 \pm 35.44$ \\
\hline GRP 4 & $6.88 \pm 0.66^{*}$ & $8.34 \pm 1.75^{*}$ & $7.54 \pm 0.37$ & $3.35 \pm 0.18^{*}$ & $60.08 \pm 8.47 * *$ \\
\hline GRP 5 & $4.98 \pm 0.97 *$ & $21.50 \pm 9.98 *$ & $7.77 \pm 0.24$ & $3.25 \pm 0.13$ & $66.06 \pm 16.43^{* *}$ \\
\hline GRP 6 & $4.40 \pm 0.25 *$ & $24.10 \pm 8.37 *$ & $7.77 \pm 0.25$ & $3.05 \pm 0.23$ & $69.35 \pm 40.00$ \\
\hline
\end{tabular}

Mean \pm SEM, $\mathrm{n}=5, * \mathrm{p}<0.05$ vs DC $* * \mathrm{p}<0.05$ vs NC

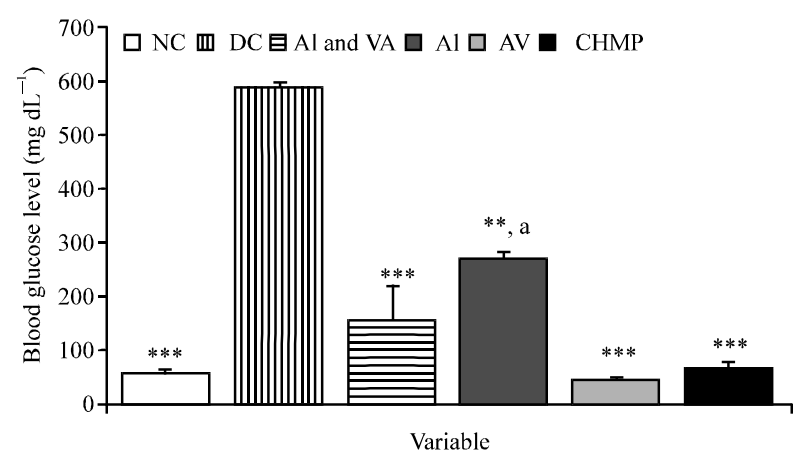

Fig. 3: Blood glucose level after 24-day treatment with extracts, $A$. indica and $V$. amygdalina combined, A. indica, $V$. amygdalina and chloropropamide in diabetic rat models. ${ }^{* *} \mathrm{p}<0.01 ; * * * \mathrm{p}<0.001$, vs $\mathrm{NC}, \mathrm{a}=\mathrm{p}<0.05$ vs DC

parameters assayed in serum of the sacrificed animals after 24 day treatment including GPT and GOT activities, protein total, albumin and urea levels. Serum GPT and GOT activities which were significantly raised $(\mathrm{p}<0.05)$ by 3.6 and 12.7 times, respectively relative to the normal control, became significantly reduced upon treatment. GPT activity significantly reduced $(\mathrm{p}<0.05)$ to $2.4,2.2,3.1$ and 3.5 times the diabetic control value in rats treated with combined extracts, A. indica, V. amygdalina and chlorpropamide, respectively. In the same order GOT activity, respectively reduced to $5.3,8.9,3.4$ and 3.1 times the value of the diabetic control. However, when compared with normal control and standard drug, extract treatments both singly and combined showed non significant differences in the aminotransferase activities. Serum urea which was 3.2 times high in diabetic control group compared to normal control, was significantly reduced $(\mathrm{p}<0.05)$ with the four different treatments. Compared to the normal control, urea level in groups treated with combined extracts and chlorpropamide were non-significant $(\mathrm{p}<0.05)$, whereas levels in groups treated with $A$. indica and $V$. amygdalina were significantly higher. Aside treatment with $A$. indica which significantly raised $(\mathrm{p}<0.05)$ albumin levels compared to diabetic control, serum protein total and albumin levels observed no changes.

\section{DISCUSSION}

The antihyperglycemic effect of ethanolic extracts of $A$. indica and $V$. amygdalina combined, A. indica, $V$. amygdalina and chlorpropamide have been evaluted in this study. The results are consistent with Sonia and Srinivasan ${ }^{[17]}$ for A. indica, Atangwho et al ${ }^{[11]}$ for $V$. amygdalina and Davis and Granner ${ }^{[17]}$ for chlorpropamide. However, from the present investigation the effect of $A$. indica on blood glucose was less than that of chlorpropamide, but significantly higher than normal control; V.amygdalina effect was more than chlorpropamide and even the normal control, though not significantly. Whereas effect of combined 
extracts on blood glucose compares fairly well with that of chlorpropamide, which itself compares well with normal control. Within the treatment period, combined extracts effect on blood glucose appears a positive synergy: A. indica could not reverse the hyperglycemic state to normoglycemic status, while on the other hand $V$. amygdalina tended towards hypoglycemia. In combined form, the extracts tend to compliment each other thereby producing the desired normoglycemia.

This observation may buttress the proposition of Tiwari and $\mathrm{Rao}^{[5]}$ as per advantage of polyherbal therapies over monotherapy. Although not fully understood, several reports have attempted insights into the hypoglycemic mechanisms of these plants. There is a report that $A$. indica does not modulate insulin effect on glycogen metabolism ${ }^{[20]}$ rather it blocks the inhibitory effect of serotonin on insulin secretion/release in pancreas of rats mediated by glucose, eventually glucose control. Sonia and Srinivasan ${ }^{[17]}$ in their report presupposed increased peripheral glucose uptake by an inhibition on the action of insulin by inhibiting glycogenesis. We have suggested in our earlier report on $V$. amygdalina that two possible mechanisms exist: one targeting insulin production from the islet cells and the second on peripheral carbohydrate mechanism ${ }^{[11]}$. Mechanisms involving insulin production are usually more potent. It's not surprising therefore that $V$. amygdalina tends to be the most potent hypoglycemic agent. More so, that other plants of the same family-compositae, such as Chrysanthemum coronariun has shown potent hypoglycaemic and anti-hyperglycaemic activity ${ }^{[10]}$.

Serum markers of hepatotoxicity-GOT and GPT were also determined. Diabetic control rats showed significantly elevated enzyme activities in serum compared to normal control. The observation is collaborative with kim et al. ${ }^{[10]}$. Upon treatment with the extracts and drug the activities of both enzymes become reduced significantly. Again, this agrees with hepatoprotective effect of $V$. amygdalina ${ }^{[22]}$ and A. indica ${ }^{[23,24]}$ against drug induced injury reported in earlier studies, although in this study the hepatotoxicity was diabetes-induced. Interestingly, in this study, A. indica appears to have a better protection against hepatotoxicity as it produced highest $\%$ reduction in GOT activity. On combination, this potency seems to boost the effect of $V$. amygdalina by increasing the percentage protection-another positive synergistic effect.

Serum total protein, albumin and urea, markers of liver synthetic ability were assessed after treatment for 24 days. Urea levels raised significantly in diabetic control group compared to normal control agrees with our earlier report ${ }^{[11]}$. All treatments reduced the hitherto raised levels of urea, but only the groups treated with combined extracts compared well with normal control and chlorpropamide. Combined extract may modulate protein breakdown in diabetes mellitus more effectively. Significant increase in albumin levels in A. indica treated groups confirms its purported most potent hepatoprotective effect, given that albumin is exclusively synthesized in the liver. It's evident from the results of this work, that whereas $V$. amygdalina alone is most potent in blood glucose reduction mechanism and A. indica most potent in protecting the liver against damage in diabetic states. Only a combination of the two extracts provided the wholistic efficacy desired in management of diabetes. Further studies to confirm this relative advantage of polytherapy is suggested.

\section{REFERENCES}

1. Ahmad, I., F. Agil and M. Owais, 2006. Modern Phytomedicine: Turning Medicinal Plants into Drugs. West-Sussex England: John Wiley and Sons, pp: 2-24.

2. Hostettmann, K., A. Marston, K. Ndjoko and J. Wolfender, 2000. The Potential of African Plants as a Source of Drug. Curr. Org. Chem., 4: 973-1010.

3. WHO (World Health Organization), 1980. Second report of the WHO Expert Committee on Diabetes Mellitus. Technical Report Series 646, Geneva, pp: 66.

4. Rates, S.M., 2001. Plants as Source of Drugs. Toxicon., 39 (5): 603-613.

5. Tiwari, A.K and J.M. Rao, 2002. Diabetes mellitus and multiple therapeutic approaches of phytochemicals: Present status and future prospects. Curr. Sci., 83 (1): 30-37.

6. National Research Council, 1992. Neem: A Tree for solving global problems. National Academy Press, Washingon DC., pp: 23-30.

7. Biswas, K., I. Chattopadhyay, R.K. Banerjee and U. Bandyopadhyay, 2002. Biological activities and medicinal properties of neem (Azadirachta indica). Curr. Sci., 82 (11): 1336-1344.

8. Abo, K.A., A.A. Adediwara and Taiyesimi, 2000. Ethnobotanical Survey of Plants Used in the Management of Diabetes mellitus in South Western Region of Nigeria. J. Med. Medical Sci., 2 (1): 20-24. 
9. Ebong, P.E., I.J. Atangwho, E.U. Eyong, C. Ukwe and A.U. Obi, 2006. Pancreatic Beta cell Regeneration: A Probable Parallel Mechanism of Hypoglycaemic Action of Vernonia amygdalina Del and Azadirachta indica. Proceedings of the 2006 International Neem Conference Kunming, China, November 11-15, pp: 83-89.

10. Kim, J.S., J.B. Ju, C.W. Choi and S.C. Kim, 2006. Hypoglycemic and Antihyperglycemic Effect of Four Korean Medicinal Plants in Alloxan Induced Diabetic Rats. Am. J. Biochem. Biotech., 2 (4): 154-160.

11. Atangwho, I.J., P.E. Ebong, M.U. Eteng, E.U. Eyong and A.U. Obi, 2007. Effect of Vernonia amygdalina Del Leaf on Kidney Function of Diabetic Rats. Int. J. Pharm., 3 (2): 142-148.

12. Reitman, S. and S. Frankel, 1956. Determination of aspartate and alanine aminotransferase in blood serum and tissues. Am. J. Clin. Path., 28: 56.

13. Thomas, L., 1998. Clinical Laboratory Diagnostics. 1st Edn. Frankfurt: TH-Books Verlagsgesellschaft, pp: 644-647.

14. Tietz, N.M., 1994. Textbook of Clinical Chemistry. 2nd End. W.B. Saunders Company, Philadelphia, PA, pp: 703.

15. Battel, L.M., V.G. Yuen, S. Verma and J.H. McNeill, 1999. Other Models of Type 1 Diabetes. In: Experimental Models of Diabetes, McNeill, J.H. (Ed.). CRC Press LLC, Canada, pp: 220.

16. Leiter, E.H., I.C. Gerling and J.C. Flynn, 1999. Spontaneous Insulin-Dependent Diabetes Mellitus (IDDM) in Nonobese Diabetic (NOD) Mice: Comparisons with Experimentally Induced IDDM. In: Experimental Models of Diabetes, McNeill, J.H. (Ed.). CCC Press LLC Canada, pp: 275.
17. Sonia, B. and B.P. Srinivasan, 1999. Investigation into the Anti-diabetic Activity of Azadirachta indica. Ind. J. Pharm., 31: 138-141.

18. Davis, S.N. and D.K. Granner, 2003. Insulin, Oral hypoglycemic agents and the pharmacology of the endocrine pancreas. In: Goodman and Gilman's the Pharmacological Basis of Therapeutics. McGraw Hill, pp: 1679-1714.

19. Gyang, S.S., D.D. Nyam and E.N. Sokomba, 2004. Hypoglycemic activity of Vernonia amygdalina (Chloroform extract) in normoglycemic and alloxan-induced hyperglycemic rats. J. Pharm. Bioresources, (1) Abstract.

20. Chattopadhyay, R.R., 1993. Effect of Azadirachta indica on leaf extract on hepatic glycogen in rats. Ind. J. Pharm., 25: 174-175.

21. Chattopadhyay, R.R., 1999. Possible mechanism of antihyperglycemic effect of Azadirachta indica leaf extract. Part V. J. Enthnopharmcol., 67 (3): 373-376.

22. Babalola, O.O., J.I. Anetor and F.A.A. Adeniyi, 2001. Amelioration of carbon tetrachlorideinduced hepatotoxicity by terpenoid extract from leaves of Vernonia amygdalina. Afr. J. Med. Med. Sci., 30: 91-93.

23. Kale, B.P., M.A. Kothekar, H.P. Tayode, J.B. Jaju and M. Mateenuddin, 2003. Effect of Aqueous extracts of Azadirachta indica leaves on hepatotoxicity induced by antitubercular drug in rats. Ind. J. Pharm., 35: 177-180.

24. Chattopadhyay, R.R. and M. Bandyopadhyay, 2005. Possible mechanism of hepatoprotective activity of Azadirachta indica leaf extract against paracetamol-induced hepatic damage in rats: Part III. Ind. J. Pharm., 37 (3): 184-185. 